\title{
NIETZSCHE DESCUBRE A DOSTOIEVSKI. NOTAS SOBRE LA LECTURA NIETZSCHEANA DE LA PATRONA ${ }^{1}$ \\ Nietzsche discovers Dostoyevski. Remarks on his lecture of The Landlady
}

Joan B. Llinares

Universitat de València

RESUMEN: Exposición del descubrimiento de la obra de Dostoievski por parte de Nietzsche, que tuvo lugar a finales de 1886 o comienzos de 1887, gracias a la lectura de L'esprit souterrain, curiosa versión francesa de dos textos del escritor ruso, la novela de juventud La patrona y una adaptación del relato de madurez Memorias del subsuelo. Siguiendo el magisterio de Joseph Frank y la senda abierta en 1973 por C. A. Miller, se argumentan algunas razones que motivaron la estima nietzscheana por aquella novela y su presentación como una pieza de música, muy extraña y muy poco alemana.

Palabras clave: música - literatura - nihilismo - Dios - cristianismo

ABSTRACT: In this paper I analyze Nietzsche's discovery of Dostoievski's work, which happened between the end of 1886 and the beginning of 1887 through his reading of L'esprit souterrain, a peculiar French version of two texts by the Russian writer, i.e., his youth novel The Landlady and an adaptation of his later years story Notes from the underground. Following both Joseph Frank's teaching and the path laid in 1973 by C. A. Miller, I argue the reasons why Nietzsche liked that book and its presentation as an awkward and barely German-style piece of music.

Keywords: Music - Literature - Nihilism - God - Christianity

\section{EL AFORTUNADO HALLAZGO DE UN EXTRAÑO VOLUMEN DE DOSTOIEVSKI}

En las cartas del 12 y del 13 de febrero de 1887 comienza a aparecer el nombre de Dostoievski en el epistolario de Nietzsche ${ }^{2}$. La carta a Overbeck del 23 de febrero expone que un zarpazo casual en una librería de Niza le puso ante los ojos la obra L'esprit souterrain, recién traducida al francés. El filósofo detectó con extraordinaria alegría su instintivo parentesco con el escritor ruso. Y describió así ese libro: «Son dos relatos, el primero, propiamente una pieza de música, de una música muy extraña, muy poco alemana (sehr undeutscher Musik); el segundo, un alarde genial de psicología, una especie de autoescarnio del gnothi sautón [conócete a ti mismo]» ${ }^{3}$. El lector puede interpretar, como han hecho varios comentaristas, que esas dos narraciones se refieren a las dos partes de que se compone el texto de la

1. El presente trabajo forma parte de proyecto de investigación FFI2008-00866: «Cultura y religión: Wittgenstein y la contra-ilustración", financiado por el Ministerio de Ciencia e Innovación del Gobierno de España.

2. KSB VIII 21 y 24.

3. KSB VIII 27-28. 
novela Memorias del subsuelo, una primera parte, titulada "El subsuelo», ensayística y argumentativa, y una segunda, denominada "A propósito del aguanieve», que es narrativa. Pero estaría en un error, pues como dice la postal que Nietzsche envió el 27 de marzo a Heinrich Köselitz hablando de Dostoievski, «me alegra que usted, probablemente, haya leído de él en primer lugar lo mismo que yo, — La patrona (en francés como primera parte de la novela L'esprit souterrain)» ${ }^{4}$. Por tanto, el ejemplar que el filósofo encontró contenía no sólo las Memorias del subsuelo, como se tiende a suponer, sino que en primer lugar recogía una novela breve del joven Dostoievski, titulada La patrona. Ese volumen daba más de lo que se podría esperar, pues lo componían dos relatos del escritor ruso. El hecho de que comenzase con el citado texto de juventud no es una circunstancia trivial, porque a Nietzsche le parecía un motivo de alegría que su amigo Peter Gast, un músico cuyas composiciones admiraba, hubiera iniciado sus lecturas del autor ruso como lo hizo él mismo, con este relato que manifiesta «una especie de música desconocida». No siempre se ha tenido en cuenta con la debida atención este juicio.

En 1930 Charles Andler expuso que L'Esprit souterrain era un volumen publicado por E. Plon, Nourrit et Cie. en París a finales de noviembre de 1886, y que la traducción que ofrecía de Memorias del subsuelo se debía a E. HalpérineKaminsky y Charles Morice. Esa traducción ha sido juzgada por los especialistas - por ejemplo, por el también traductor del ruso Boris de Schloezer- como «una adaptación extremadamente libre» de la citada novela de Dostoievski. El estudio de ejemplares de dicha edición confirma que no se limita a Memorias del subsuelo, sino que está formada por dos novelas breves, es decir, que tiene dos partes, la primera, de 152 páginas, titulada por los editores franceses Katia, corresponde a la novela La patrona, traducida con bastante fidelidad de la versión original rusa de 1847, y la segunda, de 142 páginas, titulada Lisa, adapta con muchísima libertad Memorias del subsuelo, obra de 1864 publicada originalmente por entregas en la revista Epocha. Esta novela que, aunque sólo fuera por el título del volumen, parece que debería tener la preeminencia, está adaptada de manera fragmentaria y muy poco respetuosa con el texto original, al que se le han añadido resúmenes y se le han suprimido muchas páginas.

Pero no acabaron en ello las intervenciones de los traductores-adaptadores: para motivar la inclusión de las dos novelas en un mismo volumen y bajo un único título la edición francesa inventa además una especie de epílogo después de la primera parte, un fragmento de tres páginas de extensión, concebidas según el modelo que proporciona Dostoievski en Memorias de la casa muerta, en las que se dice que el personaje Vasili Mijáilovich Ordínov, el héroe de La patrona, es también el "hombre del subsuelo», el autor, ya fallecido a sus sesenta años, del manuscrito de las confesiones que forman la segunda parte del volumen, un documento privado que ha sido posible rescatar, así dicen, de las manos de Apollón, el criado personal que tenía dicho personaje durante su relación con Liza. En fin de cuentas, por tanto, ese curioso volumen contenía, según la propaganda de sus editores, las dos principales «veleidades amorosas» del difunto Ordínov.

4. KSB VIII 50. Esta carta documenta la recepción por parte de Nietzsche de un volumen, Erzählungen von F. M. Dostojevskij, con traducciones de W. Goldschmidt, Leipzig: Reclams Universal-Bibliothek, 1886, así como el hecho de que las comparase críticamente con las traducciones francesas que ya conocía, la de La patrona en concreto. 
De ahí la correcta descripción que Nietzsche hace del libro en sus cartas: L'esprit souterrain contiene «zwei Novellen». La primera - la versión francesa de La patrona - es, en su opinión, una pieza de música, de música muy extraña y nada alemana, y la segunda —una libérrima adaptación muy reducida de Memorias del subsuelo- es, a sus ojos, un alarde genial de psicología ${ }^{5}$.

Así las cosas, el lector del volumen difícilmente podía imaginar que estaba ante dos textos pertenecientes a dos épocas muy diferentes de la obra de Dostoievski, la de juventud y la del inicio decisivo de su madurez, distantes uno del otro nada menos que diecisiete años, y que habían sido traducidos y adaptados de manera tan particular y tan abusiva, condenados a tener que compartir un mismo protagonista. En consecuencia, es obvio que si queremos analizar con rigor la recepción nietzscheana de la obra del novelista ruso hemos de remitirnos a ese libro francés de finales de 1886, con sus ocurrentes aciertos, sus notorias lagunas y sus lamentables arbitrariedades y manipulaciones. Así lo haremos, aunque más que una investigación histórico-crítica de aquel encuentro y de las imperfectas mediaciones que lo posibilitaron — por ejemplo, señalando errores y omisiones en la traducción-, nos importa clarificar nuestras propias lecturas de los textos de Dostoievski y de Nietzsche y exponer cómo se entabló ese diálogo apasionado por parte del filósofo con dicha edición francesa de aquel poderoso escritor, tan singular y desconcertante, que por entonces ya había fallecido, pero que, por muchos motivos, reclamaba su atención y ahora reclama nuestros análisis.

Aquí nos centraremos en la primera parte de L'esprit souterrain, esto es, en la novela breve titulada La patrona, porque por sí misma provoca una considerable sorpresa, un interrogante que merece clarificación. Para Nietzsche, por lo que dan a entender sus cartas, dicha parte es una genuina y muy afortunada presentación del arte de Dostoievski, una puerta recomendable para entrar en su universo más propio, cuando la crítica literaria rusa, comenzando por Bielinski — quien, decepcionado, dijo al leerla: «iEs la peor de las necedades!» y, en la reseña que le dedicó, escribió este durísimo juicio: «En toda la novela no hay ni una palabra, ni una frase sencilla y viva. Todo es rebuscado, tenso, enfático, artificial y falso» ${ }^{6}-$, la consideró una fallida obra de juventud, una de las más débiles creaciones de su autor, todavía inmaduro e inexperto, echada a perder además por las prisas, como reconocía éste años después, lamentando la violencia que tuvo que hacerse para darla a la imprenta ${ }^{7}$. En efecto, la crítica la ha visto como muy dependiente todavía de Gógol y de Hoffmann —en especial, de los relatos Der Magnetiseur, Der unheimliche Geist y Der Sandmann - , como un producto típicamente romántico, secundario y deficiente, en pocas palabras: como un mediocre engendro de un discípulo ruso de Paul de Kock. Henri Troyat, por ejemplo, la describe como inspirada en La terrible venganza de Gógol, pero añade que no se trata de una simple imitación literaria, puesto que el héroe es un retrato del propio Dostoievs-

5. En la edición de Obras completas de Dostoievski dirigida por A. Vidal para la editorial Vergara, La patrona ocupa 84 páginas mientras que Apuntes del subsuelo abarca 117 páginas (de ellas, 37 forman «El subsuelo» y 80 «A propósito de la nieve sin cuajar», lo cual indica que la edición francesa que Nietzsche leyó le dejó sin conocer el texto de unas 40 páginas aproximadamente de esta segunda novela, más de un tercio de su totalidad).

6. Cit. por Henri Troyat, Dostoievski, trad. de I. Andresco, Barcelona: Salvat, vol. I, 1988, p. 96.

7. Cf. carta a A. A. Krayevsky de 1 de febrero de 1849. Dostoïevski, Correspondance, t. 1, Paris: Bartillat, 1998, pp. 299 ss. 
ki en su juventud y de cierta pasión amorosa que vivió por entonces con Avdota Panayeva, rescatando así la candente implicación personal del escritor, su faceta autobiográfica ${ }^{8}$. Edward H. Carr es más cruel, pues afirma que La patrona reúne méritos para ser considerada como una de las peores novelas que se hayan escrito: «Para un lector moderno muy alejado de los trasnochados convencionalismos de la novela fantástica, el relato parecería un asombroso cúmulo de tonterías» ${ }^{9}$. Incluso Joseph Frank reconoce que, «definitivamente, Dostoievski se excede en el empleo de adornos góticos y románticos que resultan innecesarios y que justifican la aversión que sentía Bielinski hacia este relato» ${ }^{10}$. Si estas críticas dan en el blanco, entonces parece incomprensible que ese pobre texto cautivara al exigente Nietzsche de la madurez y le pusiera en la pista de una de las sorpresas fundamentales de su vida. Y resulta muy discutible, por lo demás, que tal opúsculo merezca que el filósofo dionisíaco lo haya considerado como una "música desconocida», «muy extraña», «una música no alemana», cuando a todas luces parece una típica pieza romántica y sentimental, un largo poema en prosa de carácter lírico, «une nouvelle romantique» ${ }^{11}$, repleta de convencionalismos, lugares comunes y frases hechas sobre recuerdos infantiles, cuentos populares, tempestades e incendios, borracheras, obnubilaciones, desvanecimientos, ensueños, pesadillas, fiebres, delirios, alucinaciones, lágrimas ardientes, amores imposibles, efusiones místicas, arrebatos religiosos, exotismos orientales, etc. Es casi imposible encontrar otro texto dostoievskiano que mejor responda a la imagen peyorativa que ofrecen los libros de Nietzsche sobre el romanticismo en cada uno de sus puntos débiles, idealistas, mentirosos, decadentes y antivitales.

Ahora bien, no todos los críticos son de esta negativa opinión, ha habido otras interpretaciones del relato que subrayan sus aciertos e innovaciones. Augusto Vidal, por ejemplo, ha escrito — aprovechando los análisis de Leonid Grossman- que «La patrona es una novela de horrores y misterios, con una nueva problemática psicológica (desdoblamiento del amor de una mujer, expiación de un pecado imaginario, fuerza de la sugestión), anuncio de lo que será el Dostoievski de la madurez. Ordínov es ya un antecesor de Raskólnikov» ${ }^{12}$, el joven pensador solitario. Para el citado analista ruso La patrona esboza ya la situación central de El idiota, una heroína que se debate entre un enamorado angelical y un criminal posesivo, y merece ser considerada como una de las premisas fundamentales de las creaciones futuras de su autor y de su específico estilo en el realismo crítico, atento a las experiencias psíquico-espirituales ${ }^{13}$. Joseph Frank precisa que «a pesar de que difícilmente se la pueda defender como pieza lograda desde el punto de vista artístico, no obstante, el paso del tiempo ha demostrado que, de las primeras obras de Dostoievski, es la que contiene mayor cantidad

8. Cf. H. Troyat, Dostoievski, cit., pp. 95-96.

9. Cf. Dostoievski 1821-1881. Lectura crítico-biográfica, trad. de A. Licetti, Barcelona: Laia, 1972, pp. 41 y 42.

10. J. Frank, Dostoievski. Las semillas de la rebelión, 1821-1849, trad. de C. H. Paschero, México: FCE, 1984, p. 421.

11. Así titula el apartado que le dedica Leonid Grossman en su importante estudio Dostö̈evski, trad. de M. Kahn, Paris: Parangon, 2003, p. 91.

12. «Dostoievski, vida y obra», en F. M. Dostoievski, Obras completas, vol. I, Barcelona: Vergara, 1969, p. 91.

13. L. Grossman, op. cit., pp. 91-94. 
de importantes anticipaciones del futuro... No es una asfixiante fantasmagoría romántica». El escritor se proponía en realidad que el tema elemental del hombre destruido por el despotismo y la subordinación incondicional, típicos del mundo ruso, se enriqueciera con un tono simbólico mucho más amplio, acorde con la historia y el folclor rusos ${ }^{14}$. Así pues, este texto contiene virtualidades insospechadas, gérmenes del mejor Dostoievski, que aquí recrea los cuentos rusos que oyó en su infancia de labios de su madre y de algunas criadas, y reconstruye una amistad de su soñadora juventud, la que mantuvo con Ivan Shidlovsky, un compañero muy religioso que pretendía escribir una historia de la Iglesia. Por su parte, Jacques Catteau subraya los rasgos comunes que existen entre esta novela de 1847 y las citadas obras de E. T. A. Hoffmann y de N. Gógol en que se inspira, insistiendo en las similitudes de la situación triangular que describen, en las concordancias de los diversos tríos amorosos que presentan. Gracias a tales antecesores el joven escritor se atrevió a aventurarse por los trasfondos desconocidos del alma humana, descubriendo el territorio inmenso de las pulsiones secretas y de los complejos que moran en el subconsciente. De este modo - explica el sabio profesor francés-, Dostoievski consiguió abordar temas inconfesables, como el complejo de Electra, la obsesión del incesto, la seducción llevada a cabo por un mediador joven y sensible, la entrega de un alma pura al poder maléfico - una versión moderna del antiguo mito del dragón y la doncella-, el aprisionamiento que conlleva la falta que no cesa de engendrarse a sí misma — llámese «pecado original» o «culpabilidad»—, el miedo devastador y paralizante ante la ascensión de fuerzas oscuras que amenazan el hogar de los ancestros... Se puede afirmar, por tanto, en opinión de Catteau, que en La patrona ya aparecen todos los motivos del mundo fantástico y del imaginario que están en relación con la crisis espiritual y cívica de la época en que se escribió, motivos que Dostoievski desarrollará en sus grandes novelas ${ }^{15}$.

Ciertamente, si damos relieve al tratamiento del trío amoroso que constituye la trama principal de este relato, en el que se dibujan al menos cuatro tríos diferentes, tres de ellos con la figura de Katia, la patrona, entonces bien podemos afirmar que el escritor ruso habría encontrado muy pronto, como prueba esta obra de juventud, uno de los factores fundamentales de su «verdad novelesca», la gestación del deseo mimético y las graves consecuencias que acarrea, superando así las trivialidades de las «mentiras románticas». En este sentido, más de veinte años antes de El idiota, El eterno marido, Los demonios y Los hermanos Karamázov, Dostoievski ya habría planteado la cuestión central en torno a la cual no cesará de profundizar, si interpretamos La patrona según las poderosas tesis antropológicas de René Girard ${ }^{16}$. Hay, pues, suficientes razones de peso que avalan una lectura atenta de este magmático texto de la juventud del escritor ruso que cautivó a Nietzsche. La tarea del hermeneuta consistirá en mostrar textualmente las dimensiones de ese relato que manifiesten un evidente aire de familia con la persona y la filosofía del autor alemán.

14. Cf. J. Frank, op. cit., p. 421.

15. Cf. J. Catteau, La création littéraire chez Dostoïevski, Paris: Institut d'Études Slaves, 1978, p. 86 .

16. Cf. R. Girard, Mentira romántica y verdad novelesca, trad. de J. Jordá, Barcelona: Anagrama, 1985 . 
En nuestro ensayo hemos de reconocer con gratitud los hallazgos del riguroso trabajo que llevó a cabo C. A. Miller en su excelente artículo «Nietzsche's 'Discovery' of Dostoievsky» ${ }^{17}$. Deseamos colaborar en la difusión de esta investigación ya clásica, publicada en Nietzsche-Studien en 1973, que siempre remite al filósofo en antiguas ediciones en alemán, al novelista en las traducciones francesas de la época, las que Nietzsche leyó, e incluso acude al original ruso para precisar los términos equívocos, y, quizá por ello, resulta de ardua consulta para varios lectores. Las citas del texto de La patrona las tomamos de la traducción francesa de Evgueni Halperine-Kaminsky y Charles Morice publicada en 1886, que es la que Nietzsche prefería ${ }^{18}$, aprovechando en ocasiones la versión castellana de Lidia Kúper de Velasco que se halla en el primer volumen de la excelente edición dirigida y prologada por Augusto Vidal de las Obras completas de F. M. Dostoievski ${ }^{19}$. Los números entre paréntesis se refieren a la paginación de estas ediciones. Quisiéramos añadir que la guía que supuso para Miller el gran libro sobre Dostoievski de Konstantin Mochulsky ${ }^{20}$, en este trabajo la ejerce la magna biografía elaborada por Joseph Frank, que, como es manifiesto, orienta nuestros comentarios. Pensamos que el principal reparo que podría hacerse al estudio del profesor Miller sería de índole metodológica, puesto que para clarificar la valoración nietzscheana de la parte denominada Katia sacrifica el episodio Lisa, dejándolo en la penumbra, cuando Nietzsche tuvo que leerlos en bloque, como apartados consecutivos de un mismo libro, y suponemos que aplicaría sobre la primera parte lo que le habría resultado valioso y aleccionador en la segunda, en una especie de compensación y de equilibrada visión de conjunto. Ciertamente, en la parte final el Dostoievski de los años sesenta critica a fondo al Dostoievski de los años cuarenta con una fuerza tal que su texto de juventud, traspuesto, bien puede interpretarse ahora con más virtualidades paródicas y carnavalescas, y con más sarcasmo satírico — para decirlo con la terminología de Bajtín- de lo que acaso sería legítimo suponer que contuviera en una lectura aislada y cronológicamente precisa. No obstante, realizar un análisis del volumen completo de L'esprit souterrain supera los límites de un artículo, y en lo que sigue nosotros también tendremos que limitarnos exclusivamente a algunos aspectos de su «primera parte». Esperamos proseguir el análisis en otra oportunidad.

\section{SUGERENCIAS PARA LA LECTURA NIETZSCHEANA DE LA PATRONA}

He aquí, al hilo de un resumen del relato, varios de sus principales elementos que pudieron interesar a Nietzsche, una vez admitido que el título general del libro

17. Nietzsche-Studien II (1973), 202-257.

18. Th. Dostoievsky, L'esprit souterrain, traduit et adapté par E. Halpérine et Ch. Morice, Paris: Librairie Plon, E. Plon, Nourrit et Cie., Imprimeurs-éditeurs, 1886. Agradecemos a Paolo Stellino el haber podido consultar este ejemplar. La «Première partie. Katia» se encuentra en las pp. 1-152. También nos ha sido útil la reedición siguiente: F. M. Dostoïevsky, L’homme souterrain (précédé de La Logeuse), trad. de E. Halperine-Kaminsky et T. de Chatrette, Éditions Résonances, 1979. El texto de La logeuse se encuentra en las pp. 29-108, y, como en la edición de 1886, forma la «Première Partie. Katia», tal como explica el editor, Thierry de Chatrette, en su «Avertissement», pp. 7-8, y en su informativo «Préface», pp. 9-28, en especial en las pp. 21-28. Esta traducción tuvo una reedición anterior, en 1928, en la editorial Plon.

19. Barcelona: Vergara, 1969, pp. 545-628.

20. Dostoevsky: His Life and Work, Princeton, 1967. 
-L'esprit souterrain - le tuvo que resultar fascinante por las hondas afinidades que el filósofo descubriría con su propio trabajo de «viejo topo», de «espíritu subterráneo», de alguien que "cava, que perfora, que mina», como dijo de sí mismo en el «Prólogo a la segunda edición» de Aurora ${ }^{21}$. El texto de esta novela breve consta en el original de dos partes, «Primera» $\mathrm{y}$ "Segunda», cada una de las cuales tiene tres capítulos o apartados (I-III), y se publicó por vez primera en octubre y diciembre de 1847. Por contra, en la edición francesa que Nietzsche leyó aparece como un bloque que consta de seis apartados sucesivos (I-VI) y todo él constituye, como hemos dicho, la «Primera parte. Katia» del libro, en la que se describe la primera aventura amorosa del personaje principal, narrada en tercera persona.

\subsection{Un alma gemela, una autobiografía similar}

La peripecia se inicia cuando el protagonista, Vasili Mijáilovich Ordínov, decide buscar un nuevo alojamiento, ya que la viuda en cuya casa tenía alquilada una habitación ha de abandonar Petersburgo. Esa decisión era difícil en su caso, porque «il était pauvre, et les logements coûtent cher» (1). De ahí que comenzara a "flâner dans les rues, en examinant les écritaux qui annoncent les locations, choisissant les maisons les plus délabrés et les plus habitées, - celles où il pouvait les plus vraisemblablement trouver un logeur presque aussi pauvre que lui-même» (2).

Se ha dicho, y con toda razón, que este comienzo pudo ganar de inmediato la atención de Nietzsche por la precisa coincidencia que establecía con lo que él mismo estaba viviendo por entonces en Niza, una zona cada vez más solicitada que le resultaba costosa, aunque benéfica por su templado clima en invierno, en ocasiones incluso demasiado desapacible y frío para su frágil bienestar. Sabemos que buscó una habitación sin humedad, bien orientada y silenciosa, de módico alquiler, en la que pudiera trabajar de manera confortable. Varias cartas de aquel invierno lo documentan ${ }^{22}$.

Más aún, bastantes rasgos de la biografía y el talante del personaje de esta novela son asombrosamente similares con los correspondientes de la vida y la personalidad del filósofo, dibujándose así un fuerte paralelismo entre ambos ${ }^{23}$. He aquí cómo el lector los va descubriendo en el texto: el hecho de salir a la calle le provoca a Ordínov gratas sensaciones porque «il respirait avec avidité l'air frais et froid; il était extraordinairement léger» $(2)^{24}$. Ese individuo «menait une existence monotone et solitaire» (3). Huérfano desde la infancia, tras graduarse en la Universidad hacía tres años que disponía de una pequeña suma de dinero, la herencia de sus progenitores que un tutor le había administrado, con la que calculó que podría vivir en un cuarto alquilado, en una especie de encierro monacal, en aislamiento absoluto, habiéndose convertido en un ser casi salvaje. Por eso recorre ahora las calles «comme un réfractaire, ou plutôt comme un ascète qui aurait brusquement quitté sa muette solitude pour entrer dans une ville agitée et

21. A, ed. G. Cano, Madrid: Biblioteca Nueva, 2000, p. 57.

22. Cf. por ejemplo las cartas siguientes: a su madre, el 22 de diciembre de 1886; a F. Overbeck, el 25 de diciembre de 1886; a P. Gast el 9 de enero de 1887, etcétera.

23. Damos por supuestos en el lector unos conocimientos mínimos de los principales constituyentes de la biografía de Nietzsche, los cuales, por elementales motivos de espacio, no detallaremos.

24. Sobre el aire libre y el pensamiento como fiesta de los músculos según Nietzsche cf. la parte final del $\mathbb{1}$ de «Por qué soy yo tan inteligente» de Ecce homo. 
retentissante» (6). El resultado de esa forzosa búsqueda es, en principio, muy baudeleriano, de joven poeta atesorando impresiones urbanas: «Il se complaisait de plus en plus en sa flânerie d'observateur» (7).

Nos hallamos, pues, ante un individuo muy particular, extremadamente solitario, que sigue su propio camino por su cuenta. «Dès l'enfance il s'était fait une réputation de singularité. Il n'avait pas connu ses parents, son caractère étrange et 'a part' lui attirait du fait de ses camarades des mauvais traitements et des brutalités. Ainsi délaisé, il devint morose, plus 'à part' encore et peu à peu tout à fait exclusif» $(5)^{25}$. "Dès l'enfance il s'était fait un vague isolement intérieur: à cette heure, l'isolement s'était précisé, défini et fortifié par la plus profonde des passions, celle qui épuise toutes les forces vitales sans laisser à des êtres comme Ordinov aucune préoccupation de la banalité pratique de l'existence, cette passion entre toute inassouvible: la science» (4). Esa pasión, la ciencia, que en sus manos «était une arme qu'il tournait contre lui-même», merece que se la denomine así — cinco veces aparece la palabra «passion» en pocas líneas, con llamativa insistencia- porque era "plutôt une sorte d'enthousiasme hasardeux qu'un dessein raisonné d'aprendre et de savoir» (5).

¿En qué consistía esa «ciencia» apasionada a la que este joven se había entregado? Joseph Frank indica que, en este contexto ruso, «tiene el significado general de 'filosofía' ${ }^{26}$. Así entendida, no se refiere a una doctrina acabada o un logro consumado, sino a un proyecto que todavía está en gestación: "C’est dans de telles dispositions qu'il s'était laissé séduire par sa passion, et il s'y livrait solitairement, sans ordre ni système arrêté. Ce n'avait été jusqu'alors que la première fougue et la première fièvre d'un artiste. Mais en lui maintenant se dressait une idée, et il la contemplait avec amour, toute vague encore et confuse qu'elle fût. Il la voyait peu à peu prendre corps et s'éclairer: il lui semblait que cette apparence implorait une réalisation. Ce désir dévorait l'âme d'Ordinov, mais il ne sentait encore que trop peu nettement l'originalité de son idée, sa verité et sa personalité. La création se manifestait déjà, elle se limitait et se condensait, mais le terme était encore loin, très loin peut-être: peut-être ne devait-il jamais venir!...» (5-6). Seguramente Nietzsche tuvo que ver descrita en estas líneas una especie de retrato de su propia infancia y juventud, e incluso de su tentativa por concluir una obra filosófica de largo aliento que por entonces planeaba. Se ha sugerido también que ese sistema soñado por Ordínov, su gran «idée», tiene las características del socialismo utópico, y de hecho la palabra «ciencia» (Nauka) se usaba en la Rusia de aquellas décadas para referirse a las teorías socialistas, tan extendidas entre determinados círculos de seguidores de Fourier $^{27}$. No obstante, ni las imágenes con las que se la describe ni el carácter de «artista» del personaje coinciden con esa concepción sociopolítica, «más bien se trata del anticuado propósito del 'soñador' idealista romántico, que considera al arte y a la filosofía caminos iguales que eventualmente convergen en el descubrimiento de las verdades superiores», dice Frank ${ }^{28}$. Varios pasajes corroboran este comentario, como

25. «En una época absurdamente temprana, a los siete años, ya sabía yo que nunca llegaría hasta mí una palabra humana», EH, «Por qué soy yo tan inteligente», $\mathbb{S} 10$, ed. cit. p. 61.

26. Ibid., p. 418.

27. Cf. J. Frank, op. cit., p. 418.

28. Ibid., p. 419. 
el siguiente: «son esprit conservait l'habitude de fuir instinctivement tout ce qui pouvait le distraire ou l'émouvoir sans ébranlement utile por la pensé» (13-14). Se configura así una fina descripción, no exenta de crítica e ironía, del «genio» idealista romántico, que ha merecido que se la considere como «el primer indicio de la relación entre el egoísmo y el 'soñador'-intelectual que posteriormente habrá de aparecer tan reiteradamente en la obra de Dostoievski» ${ }^{29}$. Repárese en que este texto se desmarca poco a poco de sus predecesores decimonónicos y comienza a mostrar una imagen distante del idealismo romántico, como Nietzsche probablemente detectó con aprobación ${ }^{30}$.

Durante esos paseos buscando nuevo lugar de residencia, Ordínov, «fidèle a ses habitudes d'esprit, il lisait dans les tableaux qui se déroulaint clairement en lui comme entre les lignes d'un libre. Tout l'intéressait, il ne perdait pas une impression. Avec ses yeux intérieurs il examinait les visages des passants, regardait attentivement la physionomie des choses, tout en écoutant avec sympathie le langage du peuple, comme s'il eût contrôlé les conclusions où l'avaient amené les calmes méditations de ses nuits solitaires» (7). Quería introducirse en la vida, que sólo conocía por sus sueños e imaginaciones; su corazón latía involuntariamente «dans une angoisse de sympathie universelle» (8). Esta presentación de la manera de pasear de un artista, de las respuestas corporales que ofrece al espectáculo del mundo, imaginamos que hubo de resultarle atractiva a Nietzsche sobre todo por la insistencia del novelista en los aspectos emotivos, desiderativos y subconscientes de tal personalidad, descrita como un esbozo autobiográfico del literato en ciernes — «sensations inconnues», «joie sereine», «soudain espoir» (2), «frissons sans cesse alternés de chaud et froid» (3), «joie et ivresse comparables à celles d'un affamé qui romprait un long jeûne» (6), «l'exaltation de l'activité» (7), «extraordinaire abondance d'impressions nouvelles» (8), etcétera-.

Ahora bien, el torbellino de la vida también produce en este temperamento ensimismado vértigo, tristeza y temor. «Une pensée encore acheva de le troubler: il revit tout son passé, isolé, sans échange d'affection... On le prenait pour un fou, $d u$ moins pour quelque grand original, - en quoi l'on ne se trompait guère. Et Ordinov se rappela que sa confiance avait toujours été ainsi repoussée, et que pen-

29. Ibid. Piénsese, por ejemplo, en Aliosha Volkovsky (Humillados y ofendidos), Stepan Trofímovitch Verjovensky (Los demonios), Andrei Petrovitch Versilov (El adolescente), e incluso en el príncipe Mischkin (El idiota).

30. Si añadimos lo que ya es explícito en el otro episodio del volumen, en la «Segunda parte», denominada «Lisa», entonces la crítica al romanticismo se evidencia con claridad, basten estas palabras del «hombre del subsuelo» del apartado VIII de esa novela (apartado XVIII de la «Segunda parte» de L'esprit souterrain, 265), cuando el antihéroe teme que la prostituta, conmovida por el recuerdo de sus sentimentales e hipócritas palabras durante el primer encuentro entre ambos, vaya a su casa: «iVendrá, me encontrará! Tal es el maldito romanticismo de todos estos corazones puros! ¡Oh, qué ruindad, qué tontería, qué limitación la de estas 'viles almas sentimentales'!» (F. M. Dostoievski, Apuntes del subsuelo, ed. cit. de A. Vidal, vol. III, p. 268). Para el problema de la crítica al romanticismo en Dostoievski y su huella en Nietzsche es deplorable que éste no hubiera podido leer una edición completa de esta novela, con los apartados enteros de la "Primera parte», «El subsuelo», en los que se hallan las burlas sobre «lo bello y lo sublime» (cf., por ejemplo, el apartado II); el apartado I de la «Segunda parte», «A propósito de la nieve sin cuajar», también contiene una notable parodia del romanticismo durante la juventud del antihéroe, con fuertes derivaciones críticas sobre el romanticismo alemán y francés, y en especial sobre los románticos rusos, muy reducidas, por desgracia, en la edición francesa que leyó el filósofo. 
dant son enfance tout le monde le fuyait à cause de son entêtement et de son allure absorbée, que sa sympathie n'avait jamais su se réveler que par des dehors ambigús et pénibles, sans égalité morale. Ç’avait été la grande souffrance de son enfance de constater qu'il ne resemblait pas à ses petits camarades. Et il était obsédé par le sentiment de cette incurable solitude» (8-9). Estas referencias a la infancia del artista, a su singularidad y a su obstinación también conmoverían a Nietzsche, avivándole recuerdos íntimos, diversas anécdotas y solitarios paseos... Por lo demás, el héroe de este relato es un «noble», que no trabaja en ninguna empresa o institución y se dedica a sus asuntos (24), de ahí que Frank lo haya descrito como el «último sobreviviente de una familia aristocrática arruinada» ${ }^{31}$. Si Dostoievski está aquí describiéndose a sí mismo en su dolorosa juventud, el filósofo alemán bien pudo imaginar que entre ellos había profundas afinidades, hasta en la supuesta ascendencia aristocrática que les caracterizaba, distanciándoles de la plebe.

En conclusión, estas primeras páginas del relato siguen cautivando a todo conocedor de la vida de Nietzsche por la exactitud con la que presentan no sólo las vivencias de quien, con una economía modesta, ha de buscar una habitación de alquiler, como así le sucedía por aquellos días en Niza, sino abundantes rasgos caracteriológicos y autobiográficos finamente insinuados, en una confesión indirecta emotivamente sentida: ascendencia noble, orfandad, estudios universitarios, temperamento artístico, solitaria excentricidad, pasión por la filosofía y la ciencia, pathos de la distancia, gusto por el aire fresco y los paseos (el flâneur), obsesión por una obra propia en proceso de gestación, ansias de comunicación, de reconocimiento y de estima, autocrítica del soñador romántico, del intelectual pasivo, sentimental e idealista, etcétera.

\subsection{Una concepción naturalista del enamoramiento: el amor como fiebre juvenil, enfermedad inconsciente, pulsión morbosa}

Ordínov llega a un barrio obrero e inhóspito de la periferia de Petersburgo. Al anochecer, entra en una iglesia en la que ha acabado el servicio religioso. Recostado en un muro, vuelve en sí cuando oye los pasos de la extraña pareja formada por un viejo alto, delgado y barbudo, de orgullosa y penetrante mirada, y por una mujer joven, de unos veinte años, de ojos azules y delicados, maravillosamente bella. Ésta se postra ante el icono de la Virgen, y después sale de la iglesia, con lágrimas en los ojos y una sonrisa en los labios, «mais son visage conservait les traces d'une terreur puérile et mysterieuse. Toute frémissante d'émotion, elle se serrait avec confiance contre le vieillard» (12). Este encuentro asombra al joven de tal modo que se ve empujado a seguirlos, a averiguar dónde viven y a pasarse la noche hechizado por la imagen de esa mujer: «Si ardente et si forte fut cette impression, son coeur suivait avec une telle prédilection les doux et tendres traits de ce visage bouleversé par la terreur et un attendrissement mystérieux, baigné par des larmes d'exaltation ou de pueril repentir, que les yeux d'Ordinov se troublèrent et qu'il sentit un feu s'allumer dans ses veines. Mais l'apparition s'évanouit. Après le transport vint la réflexion, puis le dépit, puis une sorte de colère impuissante» (14-15).

Al día siguiente, y a pesar de haber conseguido alquilar pronto una habitación adecuada, el joven regresa a la iglesia en la que había visto a la pareja y se arrodilla

31. Ibid., p. 418. 
junto a la mujer, la cual, con sentimientos ambiguos y antitéticos, otra vez musita una ardorosa plegaria. "Ses traits, comme la veille, trahissaient une émotion et une piété infinies. Comme la veille, des larmes ne cessaient de couler et de se consumer sur les joues brûlantes, comme pour laver quelque terrible crime» (18).

Este segundo encuentro produce en él un dolor sordo, insoportable: «Enfin, n'y tenant plus, la poitrine convulsivement opressée, il éclata en sanglots et heurta de sa tête en feu les dalles glacées. Il n'entendit, il ne sentit rien, sauf au coeur, comme s'il allait cesser de battre, un spasme douloureux» (18). El sentimiento amoroso se manifiesta como «cette effervescence» o impulso del corazón que quizá se debía a "tous ces efforts désordonnés et toutes ces impatientes émotions de l'esprit» (18). Lo cierto es que "Ordinov ne pouvait se rendre compte de son état, il avait à peine conscience de lui même...» (19). El enamoramiento tiene lugar, así pues, en un nivel en el que poco interviene la conciencia de aquel que lo sufre, es un movimiento pulsional lleno de tensión.

Podríamos pensar que tal fenómeno es un rasgo exclusivo de los seres humanos, e incluso de determinados humanos, sensibles y soñadores, pero el texto vuelve a desmentir ese supuesto romántico, ya que lo sitúa en su lugar natural, como si fuese una especie de fisiología meteorológica, de fiebre cósmica, de estallido corporal: "comme dans un jour de chaleur étouffante le ciel s'obsurcit tout à coup, puis se décharge sur la terre altérée en pluie chaude qui suspend des perles aux branches vermeilles, et froisse l'herbe des champs, et courbe au ras $d u$ sol les corolles délicates des fleurs: mais au premier rayon du soleil tout renaît, tout se relève, tout s'élance au-devant de la lumière et solennellement lui envoie jusqu'au ciel, pour fêter cette renaissance, d'abondants et doux effluves de joie et de santé...» (19). El enamoramiento es, pues, un simple fenómeno natural, un súbito cambio atmosférico, como la lluvia en verano.

Pero la joven no está sola, cuando acaba el oficio religioso reaparece el viejo y la toma de la mano. "Ordinov subit de nouveau le regard moqueur et menaçant, et une sorte d'étrange rancune lui serra le cour» (19-20). La mujer ya tiene un hombre orgulloso que la protege y con el que vive. No obstante, al día siguiente Ordínov se dirige al apartamento de la pareja y pregunta si tienen una habitación para alquilar. La joven contesta afirmativamente y el visitante se instala de inmediato como nuevo inquilino. "Ordinov ne comprenait guère comment tout cela avait pu arriver, mais cela le laissait indifférent» (25). La pulsión amorosa -la dinámica del deseo, la aparición de los celos y del rencor- le ha guiado en tal decisión, al margen de la conciencia y la reflexión: la presencia de otro hombre, de un rival, todavía acrecienta la velocidad de las reacciones.

\subsection{Inconvenientes de la historia para la vida: el peso de la tradición como parálisis y como esclavitud}

Una vez alojado el protagonista en el apartamento del viejo Iliá Murin y de su compañera Katerina, el relato se transforma en una sucesión de incidentes de creciente espectacularidad. Ordínov enferma y permanece en su lecho en estado de delirio; cuando no está postrado por la fiebre, está perdido en el éxtasis sensual que le provocan las caricias de la joven. Ésta alterna los abrazos apasionados con su nuevo inquilino y la atención embelesada a los libros herejes sobre los raskólni$k i$ que le lee Murin, o a los salvajes relatos de éste sobre hazañas de bandidos en el 
Volga. En una ocasión, al irrumpir el enamorado en la habitación de la pareja, el viejo dispara su escopeta sin herirlo y sufre un ataque epiléptico. Días después, tras beber unas copas y sentir el mordisco de los celos, Ordínov está a punto de apuñalar a Murin, inconsciente por el alcohol, pero tiene la impresión de que éste se le ríe con «ce rire glacial et meurtrier» (125) que le hiela la sangre y le hace temblar. Incapaz de liberar a la «patrona» de sus lazos con el viejo, ha de asumir la derrota y marcharse de allí, retornando a la habitación que previamente había alquilado ${ }^{32}$.

Esa «extraña» pareja formada por un viejo de fuerte personalidad y una débil joven que le está sometida constituye un enigma a descifrar: el secreto de ese sometimiento estriba no en la realidad misma, sino en lo que ella cree que es la verdad. Katerina está convencida de que Murin fue (y acaso todavía lo es) el jefe de una banda de asaltantes del Volga, el cual en otro tiempo, cuando todavía era fuerte y atractivo, fue amante de su madre, y cree que ella es hija ilegítima de ese individuo. A pesar de lo cual, aceptó las insinuaciones amorosas que le hacía y se fugó con él al morir su padre (presumiblemente asesinado por el bandido), durante un incendio que destruyó todas las posesiones de la familia, abandonando a su madre que agonizaba. Lo que la conquistó fue la excepcional seguridad que tenía Murin de que ella no podría dejar de obedecer sus deseos, y el juramento de dejarla en libertad cuando ella lo desease ${ }^{33}$. Pero pronto descubrió que, al dejarse dominar por él, ya no le será posible escapar de su poder. En un primer momento parece que el forajido la tiene dominada por el sexo; pero, cuando Ordínov la conoce, Murin es un anciano enclenque y su poder se ha vuelto más sutil. Ha hecho comprender a la joven que cometió el «pecado imperdonable» (el incesto), y la tiene asustada con el fantasma de la condenación eterna $^{34}$. La tortura leyéndole libros de los Antiguos creyentes e insinuándole que sus plegarias no serán atendidas. Lo peor de todo es que la joven ya ha llegado a sentir placer en su propia aflicción, a encontrar felicidad en su postración, y se ha quedado sin fuerzas para alterar su conducta. Murin es poderoso a sus ojos tanto desde un punto de vista mágico o pagano, como también desde las creencias ortodoxas cristianas; él la domina como brujo, como adivino y hechicero, y como sacerdote, como padre y guía espiritual. Luego volveremos sobre ello.

Así pues, hay argumentos para afirmar, como hace Frank, que «el tema central de La patrona es la 'libertad'»35, imposibilitada por la deformación psíquica sufrida por una persona débil, dadas las condiciones de vida de la sociedad rusa del momento. Si se destaca el contexto socio-histórico del relato, entonces cobran relieve las críticas a las supersticiones de la religión tradicional, el temor y temblor que ocasionan con la creencia en la condenación eterna por supuestos pecados pasionales que responden a pulsiones de la naturaleza humana. De ahí que se haya

32. Todo cuanto ocurre en el relato tiene un carácter misterioso, muchas cosas son tan extravagantes que Ordínov se pregunta varias veces si no está sufriendo alucinaciones. Tampoco se aclara si Katerina es una demente, o si narra una historia extraña pero verídica, ni sabemos con claridad si Murin perdió sus antiguas posesiones de comerciante en un incendio. Su persona tiene además rasgos de mago, de brujo o chamán, de adivino y hechicero, si bien no desea que se le considere impío o hereje.

33. Resuminos la novela según la lectura que propone J. Frank, cf. op. cit., p. 421.

34. Ibid., p. 422.

35. J. Frank, op. cit., p. 423. Casi lo primero que le dice Katerina a Ordínov, incitándole a que se levante y a que abandone el lecho-prisión, una vez superada su primera enfermedad, es lo siguiente: «La liberté est meilleure que le pain, plus belle que le soleil» (31). 
visto en la novela, en coherencia con otros textos de ese momento, un ataque al eslavofilismo orientado hacia el pasado, hacia lo autóctono y lo folclórico-tradicional, hacia el supuesto carácter noble y generoso del pueblo ruso y su sagrado sentido de la hospitalidad — citada con evidente ironía en el texto, "Ô sainte hospitalité de la terre russe!» (137)—. Como ha dicho Rudolf Neuhäuser en una sugerente interpretación, tras «siglos de sometimiento a tradiciones nacionales y religiosas, el espíritu ruso ha llegado a embriagarse con un complejo narcisista de autolaceraciones y goce de la humillación, y no tiene fuerza para renunciar a esas tradiciones que lo mantienen oprimido» ${ }^{36}$. Por consiguiente, puede pensarse que el autor de Ventajas e inconvenientes de la historia para la vida leería este relato con creciente pasión, como una crítica simbólica y muy precisa a los peligros del historicismo de la época, generador de indiferencia generalizada, de pasiva aquiescencia, de inseguridad personal, de pérdida de fe en las propias fuerzas ${ }^{37}$.

\subsection{La voluntad de poder en las relaciones entre los sexos y los individuos: la psicología del corazón débil y del individuo débil}

Una de las mayores aportaciones del ensayo de Miller sobre este relato se encuentra en la mostración de aquellos elementos que la profunda psicología de Dostoievski saca a la luz, en perfecta consonancia con la concepción que de ésta tiene Nietzsche, a saber, como teoría de la morfología y la evolución de la voluntad de poder. Esta interpretación se comprueba por partida doble en las dos relaciones centrales que configuran el trío protagonista de la novela, la que mantiene Murin con Katerina, ejemplo del corazón débil femenino, y la que aquél entabla con Ordínov, modelo éste de individuo débil, lo cual permite generalizar el fenómeno en todo tipo de relaciones interpersonales entre fuertes y débiles como cumplimiento de una ley universal. De ahí arrancan dos tipos básicos de moral, la moral de los señores y la moral de los esclavos, añadiría Nietzsche.

El primer caso expone qué es el amor entre los sexos, una guerra a muerte entre ellos, como ya decían muchos griegos desde la época arcaica y Nietzsche percibe en la naturaleza, una lucha entre poseer y ser poseído, ejercer el poder y ser gobernado por la voluntad de quien da las órdenes, entre lo masculino entendido como el polo activo y lo femenino concebido como pasividad y receptividad. En este relato el viejo Murin es consciente del daño que le ha hecho a su hija-amante, pero considera la situación como inevitable, como concreción de una norma universal que no depende de los deseos de los humanos, una regla de la estructura de la realidad que decreta que las personas débiles son incapaces de ser libres, y que las mujeres son seres así, corazones débiles y sumisos. De hecho, Katerina siempre se comporta como tal: por ejemplo, siendo muy joven, la primera vez que Murin se fija en ella como mujer después de haber provocado una pelea con su madre, éste le pone su navaja en las manos y le pide que le castigue por todo el mal que le ha hecho, pero ella no se atreve y sólo sabe mirar impúdicamente a su madre sin dejar de sonreír con risa insolente (84). Unos días después el bandido vuelve por la noche a visitarla y ella le abre la ventana de su

36. Cit. por J. Frank, op. cit., p. 424.

37. Cf. F. Vercellone, op. cit., pp. 57-59. Agradezco al profesor Vercellone que me indicara esta pertinente relación del primer Nietzsche con el joven Dostoievski. 
alcoba, entonces, aunque éste le ofrece una cuerda para que lo ate y lo entregue por todas sus fechorías, ella misma es la que le abre las puertas de su casa y la que luego le facilita la huida, acompañándole en la escapada (87-92). Más aún, a pesar de que siente rabia por el amor que le tiene a ese sujeto tan peligroso («c'était la colère d'amour»), no sabe contener su loco corazón («mon coeur était fou»), como dice, y le vende su alma por un pecado mortal ("Je t'ai vendu mon âme par un péché mortel» [93; 596-597]), pues Katerina es inconsecuente, impulsiva y voluble. Pero lo que en el fondo la retiene junto a él es la «gran promesa» que le ha hecho: «mientras tú seas dichosa, yo seré tu señor; mas en cuanto dejes de amarme, no me lo digas, no gastes palabras, no te molestes; basta un solo movimiento de tus divinas cejas, una sola mirada de tus ojos, un solo gesto de tu meñique para que te devuelva tu amor y tu dorada libertad, sólo que entonces... ihabrá llegado el fin de mi vida!» $(94 ; 597)$. El alborozo que entonces siente («et je sentis toute ma chair sourire à ces paroles») es engañoso, ese trato que le ha propuesto su raptor la ha retenido de por vida, el relato de sus relaciones con Ordínov confirma su ilusoria impotencia y su permanente esclavitud, como un ave que jamás abandona la jaula, por mucho que vea que la puerta está abierta y que estará acompañada en sus vuelos si se escapa.

En efecto, desde el principio se siente muy atraída por el nuevo inquilino, pero sólo le brinda una relación fraterna, de hermanos («nous vivrons comme frère et soeur» [34] y «tu auras une soeur au lieu d'une liouba [bien-aimée]... Prends-moi donc pour ta apetite soeur» [72]). Cuando ya son evidentes el amor y las repetidas caricias entre ambos - Murin detecta en seguida que Katerina y Ordínov no se quieren como hermanos, sino que se relacionan "comme deux amoureux» (109)—, ella sigue interpretando como inalterable su situación de hecho y la convierte en fundamento de su resignada pasividad; en el fondo no vislumbra más alternativa que un mero cambio de amo: «je voudrais te donner pour ton amour ma vie et la chère petite liberté, car il est doux d'être même l'esclave de celui dont on a le coeur... Mais ma vie n'est plus à moi, et la chère petite liberté est perdue» (73). Lo mismo le dice a Murin: «Bois au bonheur de ta fille bien-aimée, ta douce esclave soumise dès le premier jour» (115).

Así pues, aunque viva con el jefe de una banda de forajidos, Katerina no es una excepción, sino un ejemplo del comportamiento de las mujeres en general. El viejo Murin expone cuáles son las características del género femenino que en ella se repiten: "L'intelligence n'est pas le lot d'une fille: elle entend la verité, mais elle ne la comprend pas. Elle a dans la tête un serpent rusé, quoique son coeur soit baigné de larmes» (120). "Il n'y a pas de malheurs pour les coeurs faibles», por eso las penas de Katerina no son sino «une trace sur la sable». La persona que posee tal constitución ontológico-genérica no puede alterar su conducta, carece de fuerzas para liberarse, y por eso Murin predice su futuro sin temor a equivocarse: «Serás la esclava de quien te ame, tú misma le entregarás tu libertad, se la darás en rehenes y no querrás recobrarla. No sabrás dejar de amarle en el momento oportuno. Tú pondrás un granito y tu seductor recogerá toda una espiga» $(120 ; 611)^{38}$. Este rasgo del talante femenino es tan obvio para el viejo conquistador que no duda en aconsejar al joven Ordínov que siga sus expertos

38. Este pasaje, en nuestra opinión, se aleja diametralmente del sentido que transmite la traducción francesa: «Tu ne seras pas l'esclave de celui qui t’aimera. C'est toi qui lui prendras sa liberté pour 
procedimientos: "Un coeur de femme n'a pas la profondeur de la mer. Tu l'apprendras par toi-même!... Pourtant je ne la contredis en rien; si elle voulait du lait d'oiseau, je lui en donnerais. Elle a de l'orgueil. Elle voudrait être libre, mais elle ne saurait que faire de sa liberté» (141). Por eso Murin la describe ante Ilich y Ordínov como "une petite tête malade!", que creció en el bosque como una campesina, pero «la tête n'y est plus... c'est un vrai coup de vent, une perpetuelle tempête. Quelle tête aimante, ardente! Il lui faut toujours un bon ami, si j'ose ainsi dire, un amoureux. C'est ce qui l'a rendue folle» (133).

Ahora bien, la debilidad del corazón no es sólo un elemento exclusivamente femenino, también Ordínov es una persona débil, un individuo sin fuerza, a pesar de su sexo masculino y de ser un aristócrata con estudios. Las carencias de sus actos lo demuestran. Por ejemplo, aunque se siente perdidamente enamorado de su joven patrona, no sabe cómo seducirla, ni cómo luchar por liberarla, no sabe qué decir («il ne savait quel mot dire» [74; 587]) y hasta comete el error de preguntarle a ella qué es lo que debe hacer para conquistarla («dis-moi comment je pourrai arriver à toucher ton coeur!» [75; 588]), como si su cuerpo careciera de resortes elementales y de dotes de mando. Cuando Katerina le cuenta la historia de sus desgracias, él pide que ella lo compadezca, que tenga piedad de él porque lo ha vuelto loco, que le diga lo que ha de hacer ("Pitié! Grâce!... A ton tour tu m'as ensorcelé... dis-moi ce que tu voudras, ordonne, je t'obéirai!»), pero ante esa anormal inversión de papeles ella deja de llorar y «un singulier sourire apparut lentement sur ses lèvres, et l'on ê̂t dit que le rire voulait percer sous ce sourire» (97). Una reacción igual, «echarse a reír», provoca el joven Aliosha en Katerina cuando éste le entrega su alma y su libertad, es decir, cuando el enamorado deja de ser quien manda y ordena, como ella ha experimentado desde que se sintió deseada por Murin, prototipo de hombre fuerte y genuinamente masculino (98; 599). La debilidad de Ordínov provoca que el viejo le gane en su rivalidad por la joven, ya que durante su estancia en el apartamento de la pareja él ha sido incapaz tanto de eliminar a ese anciano epiléptico como de conseguir que ella le prefiera como compañero de vida. Su contrincante formula con lucidez el diagnóstico de sus deficiencias, pues no sólo le tilda de excesivamente joven y ardiente, afirma además que es "comme une fille abandonnée qui essuie ses larmes avec ses manches» (141). En resumen, Ordínov no es un verdadero hombre, tiene rasgos femeninos e infantiles.

Por el contrario, Murin tiene las cosas claras, para él hay dos tipos fundamentales de humanos, los fuertes y los débiles, y con esta premisa antropológica ve justificado tanto su comportamiento con respecto a Ordínov como su posesiva relación con Katerina: «Oui, vous n'avez pas d'expérience, vous ne savez pas qu'un coeur faible est incapable de se conduire. Donnez-lui tout: il viendra et vous le rendra. Donnez-lui un royaume: il viendra se cacher dans votre bottine... Oui, il se fera assez petit pour cela. Sonnez-lui la liberté, il se forgera lui-même de nouvelles chaînes. La liberté n'est pas faite pour les coeurs faibles...» (141-142). Repárese en que Murin subraya una característica general, de rango ontológico, que se concreta tanto en el caso masculino de Ordínov, incapaz de atacar y matar a su enemigo en un combate a muerte por la amada — «... que fait-on? Vous le

ne jamais la lui rendre. Mais quand tu voudras l'aimer à ton tour, tu ne le pourras. C'est un grain que tu auras semé, et un ravisseur viendra, et il prendra tout l'épi». 
savez vous-même, dans un moment de colère on prend un poignard! Ou encore, on attaque son ennemi dans son sommeil et on lui déchire la gorge avec ses dents! Mais si alors on te mettait le poignard entre les mains et ton ennemi t'ouvrait de lui-même sa poitrine, va! Tu reculerais!...» (142) - como en el caso femenino, típico, de Katerina, la eterna hija sumisa, la amante arrepentida y paralizada, la creyente atormentada que ha perdido la salud mental.

La fallida relación de Ordínov con Katerina, tal como la describe Dostoievski, guarda paralelos con aspectos de la concepción nietzscheana de las relaciones hombre-mujer, como prueban estas sentencias de Así habló Zaratustra: «¿A quién odia más la mujer? - Así le dijo el hierro al imán: 'A ti es a lo que más odio, porque atraes, pero no eres bastante fuerte para retener'. / La felicidad del varón se llama: yo quiero. La felicidad de la mujer se llama: él quiere... Y la mujer tiene que obedecer y tiene que encontrar una profundidad para su superficie. Superficie es el ánimo de la mujer, una móvil piel tempestuosa sobre aguas poco profundas. / Pero el ánimo del varón es profundo, su corriente ruge en cavernas subterráneas: la mujer presiente su fuerza, mas no la comprende ${ }^{39}$.

La visión naturalista y agónica del amor entre los sexos según Nietzsche aparece claramente formulada, por ejemplo, en estas líneas de El caso Wagner, comentando la música de Bizet: «iPor fin, el amor, el amor que ha vuelto a traducirse al lenguaje de la naturaleza! iNo el amor de una 'virgen superior'! iNingún sentimentalismo a lo Senta! iSino el amor como fatum, como fatalidad, cínico, inocente, cruel - y, precisamente por ello, todo él naturaleza! iEl amor, la guerra es uno de sus medios, su fundamento es el odio a muerte entre los sexos! ${ }^{40}$.

\subsection{Un caso germinal y paradigmático de psicología del masoquismo}

Si proseguimos una lectura detallada de La patrona en aquellos hallazgos psicológicos que pudieron atraer y enseñar a Nietzsche, Frank ha escrito un agudo comentario que consideramos certero, no sólo porque destaca el decisivo papel de este relato en la transición de Dostoievski hacia su madurez artística, sino por la rica mina que en él descubre: "Con el personaje de Katerina, por primera vez se concentra en la psicología del masoquismo, y empieza a explorar el 'placer' sutil y patológico que puede obtenerse de la autoflagelación y el autocastigo» ${ }^{41}$. Ciertamente, cuando ella le cuenta a Ordínov la génesis de su historia amorosa con Murin, con esos tremendos agravantes que son la maldición de su madre, el incendio de la fábrica —esto es, de su patrimonio familiar-, la muerte de su padre y la voluntaria fuga con el bandido sabiendo que es su padre biológico, ella reconoce que nada de todo eso constituye su auténtico mal, la genuina causa de su tormento, aunque mantener esa vieja relación incestuosa signifique su condenación para siempre; no, no es nada de eso lo que más la tortura, la verdadera tragedia que atraviesa la vida de Katerina es de otra índole, y ella es perfectamente consciente de en qué radica, ya que lo expone con meridiana claridad: «Mon plus grand chagrin, celui qui me rend l'âme amère, c'est que je suis l'esclave enchantée de ma honte, c'est que j'aime mon opprobe, c'est que je me complais comme en

39. Za, «De viejecillas y de jovencillas», p. 111.

40. Escritos sobre Wagner, ed. cit., p. 192.

41. Ibid., p. 425. 
un bonheur au souvenir de mon déshonneur! Voilà ma misère! Mon coeur est sans force et sans colère contre mon peché...» (96). Lo que la joven enferma no percibe en esta confesión es que no ha llegado ella sola, por ella misma, a sentirse dichosa en su cautiverio, porque en realidad durante años ha sufrido un largo proceso de adoctrinamiento que la ha hecho sentirse pecadora. En seguida lo analizaremos.

Pero antes, resumamos la tesis que aquí deseábamos presentar: «Es sólo en La patrona donde Dostoievski comienza a comprender las implicaciones de esta psicología [del masoquismo] y a explotar seriamente sus posibilidades. El eje de su interés artístico se traslada, del conflicto interior causado por actitudes condicionadas por la sociedad, a la lucha del individuo con su propio carácter. Katerina es todavía víctima de Murin y de todas las fuerzas oscuras que él representa; pero también es víctima de su incapacidad para dominar el 'placer' que obtiene de su sometimiento y degradación. De este modo, se añade una nueva dimensión a la descripción que hace Dostoievski de la personalidad, y que consiste en trasladar al propio individuo parte de la responsabilidad moral de su propio destino ${ }^{42}$. He aquí, según Frank, la importancia de este relato, pues contiene el primer indicio de un cambio en la interpretación del carácter individual, que evoluciona desde lo psicológico-social hasta lo psicológico-moral, con lo cual ya se perciben en él anticipaciones de los grandes logros de obras futuras, como Las memorias del subsuelo, Los demonios o Los hermanos Karamázov.

\subsection{La psicología del sacerdote y la crítica al cristianismo}

Según la antropología filosófica de esta narración, en todas las relaciones interpersonales está en juego la voluntad de poder, la fuerza y la debilidad de quienes las entablan. Ésa es la "pensée terrible» que, en las últimas páginas del relato, Ordínov llega a considerar tras las experiencias que ha vivido como «une probabilité, une realité» (147). Ahora bien, lo que entonces intuye como verdaderamente terrible es algo todavía más complejo, cuyo comprensión requiere que se atienda a los mecanismos que se ponen en juego en el diálogo interpersonal y a los efectos que produce en el transcurso del tiempo. Entonces se consigue entender que las fuerzas de una persona no son una dotación fija y constante, sino un plexo de elementos cambiantes en dinamismo vivo, susceptibles de sufrir alteraciones, de cambiar de dirección y de sentido, en parte gracias a las interpretaciones que reciben en los combates y flujos en que dichas fuerzas se hallan inmersas. Los individuos, así pues, se van constituyendo y redefiniendo al interactuar y conversar con otras personas, configurándose así una psicología propia con perfiles definidos. Veamos cómo lo resume el narrador al sacar conclusiones de la personalidad de Katerina desde la perspectiva de Ordínov y de la historia entera que nos ha contado: "Il lui semblait, et il finit par y croire, il lui semblait que l'esprit de Catherine était sain et que pourtant Mourine avait raison de l'appeler 'coeur faible'. Il lui semblait qu'un mystère inavouble la liait au vieillard, mais qu'elle n'avait pas la conscience du crime et qu'elle se soumettait innocemment à cette domination infâme. Qu'étaient-ils l'un pour l'autre?... Son coeur battait d'une colère impuissante en songeant à la tyrannie qui pesait sur ce pauvre être. Les yeux épouvantés de son âme tout à coup voyante sui-

42. Ibid., p. 426. 
vaient la pauvre fille dans la chute progressive qu'on lui avait savamment et traîtresement ménagée: comme on l'avait torturé, le faible coeur! Comme on avait méchamment interpreté contre lui les textes immuables! Comme on l'avait parfaitement aveuglé! Comme on avait avec adresse exploité la fougue de sa nature! Et, peu a peu, voilà qu'on avait coupé les ailes de cette âme née libre et maintenant incapable de prendre son essor vers la vie...» (147).

La triste situación de Katerina, por tanto, es incomprensible sin Murin, un personaje que actúa con los rasgos de una especie de «sacerdote» con sus fieles, subrayando los pecados y prescribiendo los correspondientes rituales de expiación una y otra vez, cavando así una fosa insuperable. Ese viejo repleto de argucias y lecturas interpreta para engañar, su «sacerdocio» es una hermenéutica perversa que produce parálisis y ceguera, que todavía debilita más a su paciente. Por otra parte, su presentación física ${ }^{43}$ recuerda a la del gran Inquisidor de Los hermanos Karámazov, y a la del anciano jubilado del capítulo de este nombre en el Zaratustra: palidez, altura, delgadez, barba semicana y una mirada de ojos de fuego. Está enfermo, padece ataques de epilepsia — como la narración detalla-, pero en todo momento maneja con gran astucia los hilos de su vida y de la de aquellos que le rodean y le visitan. Veamos cómo.

En su primera aparición en el relato hace profundas reverencias en el centro de una iglesia, toma de la mano a su mujer y la conduce hacia la imagen de la Virgen, cubriéndole la cabeza con el manto que colgaba del altar $(11 ; 553)$. La joven sale llorando y sonriendo, llena de temor y de espanto, como si fuera una niña que temblara de emoción. Idénticos rasgos antitéticos — risa y llanto, alegría y pena, fascinación y espanto- manifiesta ante la lectura de un libro religioso por parte del viejo $(45 ; 571)$, y ante Ordínov, cuando el viejo está inconsciente, reaccionando ante la epilepsia de éste como una niña pequeña, asustada y temblorosa $(68 ; 584-585)$. Las oraciones, las lecturas piadosas y los ataques enfermizos se repiten con adictiva periodicidad, con morboso placer.

Ya en el primer diálogo que tienen Ordínov y Katerina, ésta le dice que «Chez mon patrón aussi il y a beacoup de livres. Veux-tu les voir? Il dit que ce sont des livres de piété, et il m'y lit toujours» (35), porque quiere saber si él le explicará lo que Murin le ha leído. Luego le pregunta si le gusta rezar, y le confiesa: «Sais-tu, moi, j'ai toujours peur, j'ai peur...» (36). Katerina vive atormentada por la religión que su compañero le alienta a mantener y a cultivar: además de las ya citadas visitas a la iglesia, en la habitación de la pareja hay libros religiosos, de gran tamaño, un icono antiguo ante el que postrarse y rezar, y una lamparilla que arde noche y día ante esa imagen (45).

La conducta de Murin tiene mucha responsabilidad en el miedo incesante y destructivo que no abandona a la joven. Las actividades que lleva a cabo cubren un espectro sorprendente y misterioso: el portero tártaro de la casa en la que viven lo presenta como un hombre enfermo, pero listo, que sabe adivinar el porvenir a cambio de dinero en efectivo (50). Yaroslav Ilich, una especie de policía de distrito, lo considera extraño y sumamente interesante, un individuo enfermo que sufre ataques, en los que una vez atentó contra un mercader y pasó

43. "De haute taille, droit encore et énergique mais amaigri et maladivament pâle... une longue barbe à demi blanche tombait sur sa poitrine, et sous ses sourcils épais et francés, le regard, hautain et pénétrant, brillait d'un état fiévreux» (10-11). 
años haciendo penitencia religiosa... Es un tipo curioso y muy instruido, un beato, un místico $(60 ; 578-579)$. Murin tiene enorme influencia sobre la gente que acude para hacerle consultas, pues es capaz de hacer sorprendentes augurios y "prédictions», posee un don sobrenatural, no es un simple charlatán, personajes similares se hallan en las obras de Pushkin... (62-63; 580). Se trata, por tanto, de un enfermo que cuida a otros enfermos, que les pronostica sus dolencias y los remedios correspondientes, de manera que, como sucede en el caso de Katerina, éstos ya no pueden prescindir de sus caros consejos y sus interesadas atenciones.

La relación amorosa de la extraña pareja, que comenzó con un regalo (un collar de perlas) y la posterior humillación de la madre por parte de Katerina, y siguió con una especie de rapto la noche del incendio, con la maldición de la madre agonizante y la muerte del padre, tiene un componente religioso marcado por la unión sexual incestuosa entendida como gravísimo pecado, y la correspondiente culpa que marca para siempre sobre todo a la pecadora: como Murin le advirtió a su nueva amante al emprender la huida, "Je viens te chercher, belle fille. Sauve-moi, puisque c'est toi qui m'as perdu. Je me suis damné pour toi! Car comment jamais expier cette nuit maudite?... Peut-être, si nous prions ensemble...» (90). Pero lo dice riéndose con maldad, como si se burlara al mismo tiempo que está produciendo temor y temblor en su frágil e inexperta compañera, a la que le atribuye su perdición y su propia condenación, alimentando así desmesurada e injustamente la culpabilidad de ella. Ambos huyen de la casa y en el bosque encuentran el caballo del padre, cosa que él interpreta así: «Dieu nous envoie un aide...» (91). Katerina se queda callada, pero Murin añade: "Je ne suis pas un hérétique, un impur; je vais me signer si tu veux!». Y, en efecto, hace la señal de la cruz para que ella se atreva a montar y se escape con él (91). Cada suceso, cada gesto, cada decisión que toman se reviste al momento, así pues, de una interpretación mágico-religiosa que encierra entre sus mallas cualquier espontaneidad natural, desvirtuándola.

Desde aquella noche "maldita» Murin no ha dejado de echar leña al fuego que arde en la imaginación de Katerina, debilitando sus energías, enloqueciendo su mente, torturando despiadadamente su sensibilidad. Ella sabe que su alma está a merced del viejo, hipnotizada como una marioneta, y así se le expone a Ordínov, en una descripción de sus tormentos tan precisa que parece redactada por un psicólogo clínico: "J'ai mal, oh! que j'ai mal! - bégaya-t-elle avec une peine infinie. Oh! Je vais mourir... Ensorcelée! on m'a ensorcelée! perdue!... Oui, ensorcelée, - continua-t-elle, le méchant homme m'a ensorcelée, lui, c'est qui m'a perdue... Je lui ai vendu mon âme... Il dit que quand il será mort, il viendra chercher mon âme... pécheresse... Je suis à lui, il m'a pris mon âme... et il me toumente! Il me lit dans les livres... Il dit que j'ai commis un péché mortel...» (7677). "Je suis toujours ainsi!... J'ai toujours peur... Et alors je vais chez lui. Parfois, pour me rassurer, il fait des incantations, parfois il prend son libre, le plus grand, et lit sur moi. Ce sont toujours des choses graves, terribles! Je ne sais trop quoi, je ne comprends pas toujours, mais ma peur redouble, il me semble que ce n'est pas lui qui parle, mais quelqu'un de méchant, qu'on implorerait en vain, que rien ne pourrait apaiser, et je me sens un poids, un poids sur le coeur!... Et je souffre plus alors, bien plus qu'auparavant!» (78). "Il me dit: Prie! prie! Et je me lève, dans le noir de la nuit, et je prie longtemps, des heures entières. Souvent je meurs de sommeil, mais la peur me tient éveillée, et alors il me semble qu'un orage s'amoncelle contre moi, qu'un malheur me menace, que les méchants veulent me tuer, et que 
les saints et les anges refusent de me défendre... et je me remets à prier, à prier, jusqu'à ce que l'image de la Madone me regarde avec miséricorde, alors je vais me coucher, comme morte. Mais quelquefois je m'endors par terre, à genoux devant l'icône et quelquefois aussi c'est lui qui me réveille: il m'appelle, il me caresse, il me rassure, et je me sens mieux, je me sens forte auprès de lui et je ne crains plus le malheur. Car il a la puissance! Il y a une vertu dans sa parole!» (78-79).

Katerina se siente una hija maldita, una asesina, se sabe la culpable de la muerte de su madre y quiere decirlo, necesita confesar su culpa, pero Murin -le dice ella a Ordínov- siempre le prohíbe que hable, «il me supplie de me taire, et pourtant, par ses reproches, par ses colères, c'est lui-même quelquefois qui ranime toutes mes souffrances. C'est mon ennemi, mon bourreau» (80). El viejo provoca el remordimiento sin vías de exteriorización, es decir, facilita el nacimiento de la mala conciencia, el surgimiento de un malestar sin remedio.

Murin no sólo ejerce un tratamiento cruel para que Katerina viva aterrorizada por su pasado, aprovechándose para ello de las creencias religiosas tradicionales sobre los pecados, las oraciones, los sacrificios expiatorios y el infierno, también pronostica el futuro como nigromante y adivino con lecturas y poderes especiales. Por eso ella le pide que le diga su suerte, que le lea la palma de la mano, ya que es un brujo experto que ha aprendido muchos libros y conoce la magia negra — «tu as étudié dans les livres et tu connais toutes les sciences diaboliques» (116)—. Se dice de él que mediante sortilegios es capaz de provocar toda suerte de desdichas. Es un adivino rodeado de libros de hechicería («les livres noirs»), que sabe predecir el futuro, cosa que él mismo admite con arrogancia: «je suis en effet un sorcier» $(119 ; 611)$.

Por último, en la decisiva escena de la mirada burlona y diabólica que paraliza a Ordínov e inutiliza el puñal que éste había cogido para matarlo, Katerina se inclina definitivamente por el viejo, quien triunfa y ríe con cinismo. Entonces el joven alcanza a comprender cómo aquél consigue controlar a la atormentada muchacha y de qué mecanismos se sirve para mantenerla bajo su dominio: "l'esprit de trahison et de supercherie, la tyrannie systématique et jalouse, voilà ce que révélait l'impudence de ce rire...»(125-126).

La compleja acción psicológica de este perverso personaje, retorcido y cruel, que combina los rasgos del brujo de las prácticas mágicas de la Rusia profunda con las plegarias y lecturas sagradas de los popes del cristianismo ortodoxo ante los iconos de las iglesias, supuso una verdadera lección para Nietzsche y le ayudó a perfilar su novedosa teoría sobre el sutil comportamiento de este tipo de personas, los «sacerdotes», capaces de debilitar a los más fuertes, que tanta incidencia han tenido, a los ojos del filósofo alemán, en la historia del pueblo judío y en la expansión del cristianismo en Occidente. Los aforismos que redactó antes de haber leído al novelista ruso no enfocan la cuestión del «sacerdocio» bajo esta perspectiva, se limitan a considerar las tareas pastorales. Gracias, pues, al magisterio de Dostoievski, y a las lecciones de este relato, Nietzsche pudo escribir La genealogía de la moral y reconocer que «este libro contiene la primera psicología del sacerdote» ${ }^{44}$. Empezaba así, provisto de nuevas armas, su combate final contra el cristianismo, su «transvaloración de todos los valores».

44. EH p. 122. 


\subsection{La inexistencia de la amistad}

El tema clásico y muy griego de la amistad también aparece tratado en este texto mediante tres sintomáticas conversaciones entre Ordínov y un funcionario de los cuerpos de seguridad del Estado, el cual, por su carácter, aparenta tener muchos amigos. En el apartado III se describe el primer encuentro del protagonista con ese antiguo conocido, el «policía» Yaroslav Ilich (51 ss.; 574 ss.), un individuo que ambiciona cultivarse, deseoso de entablar relaciones con quienes por sus modales parecen «dignos de pertenecer a la alta sociedad». En seguida se muestra satisfecho de poder decirle a Ordínov que es «amigo sincero» — «e suis avec lui, $j$ 'ose le dire, sur un pied d'intimité» $(57 ; 577)$ - del viejo propietario de la casa en la que está alojado. Dicho personaje, por lo general bien informado de la vida y milagros del vecindario, se siente conmovido por haber encontrado un viejo amigo - «il était ému par la rencontré de son ami» $(63 ; 580)$ - por haberle podido contar cosas interesantes de la extraña pareja que le ha alquilado la habitación, y, al despedirse de él, «serra comme dans un étau la main 'd'un de ses meilleurs amis'» (64; las comillas están en el texto y no deben pasar desapercibidas, son un guiño del narrador). Más adelante, cuando Ordínov ha fracasado en su relación con Katerina y decide cambiar de residencia, se encuentra en el despacho de Ilich a Murin, quien se le ha adelantado argumentando la conveniencia de que deje el alquiler. El viejo cuenta su versión de lo que ha sucedido en el apartamento ante tan cualificado testigo y pide expresamente que Ordínov se marche, aunque mantiene cortésmente su hospitalidad. El joven queda anonadado y perplejo, ya que se ha puesto en ridículo ante el representante de la autoridad por la presteza y las artimañas de Murin. Ilich hubiera reventado de risa si ambos hubieran estado solos, pero tuvo que reprimir su hilaridad y frenarse, guardando las formas. Entonces el narrador escribe entre guiones, con evidente ironía, este comentario: «- de pareils amis! — idos amigos tan buenos como eran!» $(138 ; 621)$. La novela acaba con un último diálogo entre ellos, que marca una especie de contrapunto con su primer encuentro: el policía aparece ahora más delgado, sus ojos han perdido el brillo y delatan sus desengaños, tiene prisa, va sucio y mojado, ha dejado que le crezcan las patillas y trata de evitar «un ancien ami» (148). Ese gesto sutil ofendió a Ordínov, quien solía huir de las muestras de compasión y de simpatía («fuyait la pitié»). ¿Por qué se sintió herido? He aquí la clarividente explicación: «Il aurait préféré qu'Yaroslav Illiitch fût encore cet homme d'autrefois, simple, naïf, un peu bête, avouons-le, mais qui, $d u$ moins, ne posait pas pour la désillusion et n'annonçait aucun projet de devenir plus intelligent. Et n'est-ce pas très-désagréable de retrouver tout à coup intelligent un sot que nous avons aimé autrefois précisément peut-être pour sa sottisse?» (148). No obstante, a pesar de haber perdido las ilusiones y de haber ganado inteligencia, el policía conserva su carácter y saluda a su viejo amigo: «Avec délices il fouilla comme autrefois dans l'âme de son ami. Il lui fit d'abord remarquer qu'il avait beaucoup a faire, puis 'qu'il y avait longtemps qu'on ne s'était vu'. Mais soudain la conversation prit une étrange tournure. Yaroslav Ilich parla d'hypocrisie des gens en general, de l'instabilité du bonheur en ce monde et de cette futilité qu'est la vie. En passat il ne manqua pas de nommer Pouchkine, mais avec une indifférence très-marquée. Il parla de ses 'bons amis' avec cynisme et s'emporta même contre la fausseté, contre le mensonge de ceux qui, dans le monde, s'appellent amis, alors que l'amitié sincère n'existe pas et n'a jamais existé». Y, como muestra de asentimiento, 
el narrador añade: «Oui, vraiment, Yaroslav Illiitch est devenu intelligent. Ordinov ne le contredisait pas, mais il se sentait très-triste. Il lui semblait qu'il enterrait son meilleur ami» (149). El policía, así pues, no sólo reconoce que nunca ha habido amistad entre ellos dos, sino que tampoco la había con el dueño de la casa en que Ordínov se alojaba, un anciano de noble apariencia, pero que en realidad era el jefe de una banda de ladrones, contrabandistas y estafadores. La amistad sincera, así pues, es una quimera inexistente. La relación de esta desenmascaradora experiencia con varios textos nietzscheanos sobre la amistad es, asimismo, muy evidente. Baste aquí recordar la conclusión del discurso «Del amigo» de la «Primera parte» de Así habló Zaratustra: «Existe la camaradería: iojalá exista la amistad!» ${ }^{45}$.

\subsection{Una pieza de música, de música desconocida, muy extraña y muy poco alemana}

Las cartas a Overbeck y a Köselitz de 1887 confirman que Nietzsche consideraba este relato como una especie de música muy especial, muy alejada de la típica música del romanticismo alemán, como la de Wagner y Brahms, a pesar de no tratarse en este caso, obviamente, de una pieza de música veneciana, o mediterránea, genuinamente italiana, como la de Rossini, o casi mora y africana, como la de Bizet. ¿A qué música se refería? ¿Y por qué es muy poco alemana? Si nos guiamos por el texto de «Nosotros, los antípodas» de Nietzsche contra Wagner, que reescribe el aforismo 370 de La gaya ciencia, distinguiremos dos tipos de sufrientes, los que sufren por la sobreabundancia de la vida, tienen una visión trágica de ésta y quieren un arte dionisíaco, y los que sufren por el empobrecimiento de la vida, los cuales desean un arte que proporcione tranquilidad y dulzura, o bien le exigen ebriedad, aturdimiento y convulsión ${ }^{46}$. Parece ser que el psicólogo Nietzsche dedujo de la lectura de La patrona que su autor creaba desde la sobreabundancia de vida, que la presencia de lo malvado, absurdo y feo, de lo terrible y problemático en este relato era lícita por el exceso de fuerza regenerante que predominaba en su creador y se traslucía en su arte antirromántico y antiidealista. ¿Puede verse todo eso en el estilo, en la manera de escribir? ¿Guarda esta escritura realista alguna relación con la música?

Leonid Grossman lo insinuó en este comentario sobre la prosa del Dostoievski de La patrona: "Les confessions des héros sont rédigées dans un style inattendu, à la façon des épopées populaires ruses, des bylines, avec des échos de chansons de brigands et de chansons d'amour, parfois dans l'esprit des poésies des vieuxcroyants, ou des cantiques des sectes, allant jusqu'à une exaltation extrême. Seul un style aussi intense, aussi tendu, correspond à l'ampleur épique du récit. C'est du romantisme effréné mais dans le cadre précis d'un essai de l'école naturelle de Pétersburg ${ }^{47}$. Esta obra es, pues, para los oídos expertos de un especialista ruso, como un conjunto de diversos cánticos y canciones de su país, religiosos y profanos, es como una especie de magna canción rusa, a veces alegre, a veces repleta de melancolía, pero siempre intensa.

Un fragmento póstumo redactado por Nietzsche en julio-agosto de 1883 dice: «La música rusa saca a la luz, con una simpleza conmovedora, el alma del mujik,

45. Za, ed. A. Sánchez Pascual, Madrid, Alianza, 1997, p. 98.

46. Cf. Escritos sobre Wagner, ed. cit., pp. 258-260.

47. L. Grossman, op. cit., p. 92. 
del pueblo bajo. Nada habla más a mi corazón que las suaves melodías de esa música, todas las cuales son melodías tristes. Yo cambiaría la felicidad de Occidente entero por la forma rusa de estar triste. - Mas ¿̇cómo es que las clases dominantes de Rusia no están representadas en su música? ¿Basta con decir 'los hombres malvados no tienen canciones'? $\gg^{48}$. Sánchez Pascual lo tradujo en la nota que acompaña a la sentencia 22 del apartado «Sentencias y flechas» de Crepúsculo de los ídolos, que dice así: «'Los hombres malvados no tienen canciones’. - ¿Cómo es que los rusos las tienen?» ${ }^{49}$. La aristocracia rusa del siglo XIX tiene canciones y tiene esa forma especial de música que es la literatura, como la de Dostoievski, podríamos decir, aventurando una respuesta a la pregunta de Nietzsche.

En efecto, si se estudia el texto de La patrona intentando rastrear - ya que no nos es posible apreciar la sonoridad del original- al menos la presencia explícita de la música en sus páginas, encontramos en primer lugar mínimas referencias al arte de los sonidos en algunas adjetivaciones y analogías reiteradas, que apuntan a la alegría y la felicidad. Por ejemplo, cuando Katerina toma la mano del joven y lo introduce en la habitación «avec un rire musical» (107). En sus primeros sueños enfermizos Ordínov presentía la cercanía de su amada y entonces oía a menudo el susurro de unos pasos próximos, ligeros, al lado de la cama, «et le murmure de paroles tendres et caressantes, douces comme une musique» (39). Posteriormente, cuando él por fin le declara su amor, «sa voix, sortant droit de son coeur, tremblait comme une corde de violon, de toute la plénitude d'un transport et d'un bonheur inconnus» (74). Más significativa es, en segundo lugar, la función rememorativa que la música cumple al menos en dos contextos, uno tiene lugar en desvanecimientos enfermizos, por ejemplo, durante el segundo ataque de fiebre y ensoñaciones que sufre el protagonista, cuando revive sus años de infancia, en los que se dormía mientras su madre, inclinándose sobre la cuna, hacía sobre él la señal de la cruz, le besaba «et le berçait de chansons de nourrice durant les longues nuits paisibles» (40). En un ataque posterior, todo lo que Katerina le había dicho en su primera conversación «résonnait encore dans ses oreilles comme une musique» (66), y unas horas después, imaginando que ella le susurraba algo cariñoso, «il reconnut cette musique qui vibrait dans son coeur» (68). La otra experiencia ocurre al final del relato, meses después de que hubiera cambiado de residencia y recuperado parte de su salud: "Il n'avait confié a personne son malheur. Mais souvent, à l'heure du crépuscule, quan les cloches lui rappelaient le momento inoubliable où il s'était agenouillé auprès d'elle dans le temple de Dieu, écoutant batre le coeur de la jeune fille et baignant de joyeuses larmes cette espérance qui traversait sa vie solitaire, alors un orage se levait dans son âme à jamais meurtrie, son esprit chavirait, toutes les tortures de l'amour recommençaient pour lui; il soufrait! il soufrait! Et il sentait que son amour augmentait avec sa soufrance» (146).

Ahora bien, no siempre la música evoca el tiempo pasado con nostalgia, ni siempre transmite pena y tristeza, como en este final; en ocasiones la música es, en tercer lugar, plena expresión de presente vivo y dichoso, de presencia amorosa y placentera, de alegría compartida y risa desbordante, de vida afirmativa y contagiosa, de felicidad que necesita comunicarse. Por ejemplo, estando en casa de su patrona, al despertar de uno de sus desfallecimientos, Ordínov oyó una voz cono-

48. Cf. CI, nota 25 , p. 152.

49. Ibid., p. 37. 
cida: «Soudain une voix chanta. C'était une harmonie comparable à ces musiques intérieures, familières à l'âme aux heures de joie» (105). Este rasgo dionisíaco y pletórico que manifiesta la música de las expresiones amorosas se percibe muy bien en el pasaje que a continuación transcribimos, sin duda el más relevante para la cuestión que hemos planteado, un texto que es algo así como la descripción fenomenológica de una canción que desea invitar a la alegría y al amor, y contiene una fina enumeración de las manifestaciones que produce en el cuerpo de un oyente sensible y enamorado la música que su gozosa amada le canta para despertarle e incitarle a la acción: «Tout près de lui, presque au-dessus de sa tête, la voix claire et ferme de Catherine chantait une chanson douce et monotone. La voix montait, s'abassait puis expirait en une plainte, comme si elle s'absorbait en l'angoisse intime d'un désir inassouvi, maîtrisé, dérobé sans issue au fond d'un coeur languissant. Puis elle reprenait en roulades de rossignol, parfait symbole d'une invincible passion, et s'épandait en une mer d'harmonies puissantes comme les premières heures de l'amour. On distinguait aussi les paroles, simples, sentimentales, mervelleusement appropiées à la mélodie. Mais Ordinov les oubliait. La musique seule le touchait. Au simple et naïf recitatif, il substituait d'autres paroles qui répondait mieux aux détours cachés, -cachés à lui-même-de sa propre passion, des paroles toutes pleines d'elle. Et c'était tantôt le dernier gémissement de la passion sans espérance, tantôt, au contraire, le cri de joie du coeur qui a enfin brisé ses chaines et se libre, libre et serein, à un noble amour. Et tântot, c'étaient les premiers serments de l'amante, la pudeur parfumée des premiers rougeurs et l'éclair des larmes, et les chuchotements mystérieux et timides; tantôt le désir stérile d'une vestale, orgueilleuse et joieuse de sa forcé, sans voiles, sans mystères, et qui, avec un rire lumineux, ouvre largement ses yeux enivrés...» (105-106). El impacto de la canción es tan fuerte, que Ordínov no pudo esperar que finalizara y se levantó de la cama, abandonando su pasividad. Aquí, la música jubilosa despierta e incita a moverse, a bailar y a abrazar...

El oyente estético que se planteaba el enigma de las canciones rusas en esta página habría encontrado parte de la solución. No se olvide que desde El nacimiento de la tragedia en el espíritu de la música Nietzsche sabía que la canción popular es el perpetuum vestigium de la unión de lo apolíneo y lo dionisíaco. Todo el capítulo 6 de ese libro permitiría un comentario sobre la enigmática frase con la que condensó sus impresiones de la lectura de La patrona. ¿Acaso no era este relato como una triste canción popular rusa, triste con esa tristeza que a Nietzsche tanto le fascinaba por la extraña afirmación de vida que venía a significar? Por lo demás, si es acertada la propuesta de lectura que hemos ido exponiendo sobre la historia tradicionalista, la voluntad de poder, los individuos fuertes y los corazones débiles, las belicosas relaciones entre los sexos, la psicología del masoquismo y de la figura del «sacerdote», el desenmascaramiento del amor y la amistad, etcétera, esto es, si para el Nietzsche maduro que está preparándose para redactar $E l$ caso Wagner y para "que la música no se convierta en un arte para mentir» ${ }^{50}$ esta novela era la obra de un artista de muy notable verdad y veracidad, no debería resultar problemático que por todo ello la considerara como una música extraña, desconocida y muy poco alemana: la «primera parte» de L'esprit souterrain, es decir, La patrona, era, en efecto, un fragmento de música rusa muy triste y veraz.

50. Cf. Escritos sobre Wagner, p. 225. 